normal fingerprints. Cummins and Midlo (1961) suggested that white lines are due to buckling of the skin. An examination of the fingers with white lines in coeliac patients does not confirm this, though we have observed two patients with Marfan's syndrome where buckling of the skin undoubtedly. did lead to white line formation. Verbov (1970), has stated that "ridge distortion" may also be seen in dry or atrophic skin "due to many causes." Though some patients with coeliac disease do have dry skin this is by no means always the case. From our findings we think that the white lines in patients with coeliac disease are merely secondary to ridge atrophy, and this is supported by the finding that white lines disappear when ridge atrophy is almost complete and reappear when the ridges begin to grow again. Possibly ridge atrophy is a manifestation of abnormal cell turnover in the skin, paralleled by similar changes of the cell turnover in the small bowel (Croft et al., 1968).

Fingerprinting of patients with coeliac disease may have two possible uses, subject to further-long-term studies being made at present: (1) As a diagnostic feature in new cases of adult coeliac disease, where it is apparently the only wasting disease where ridge atrophy is seen; (2) as a measure of a full response to a gluten-free diet. If fingerprint changes correlate closely with villous atrophy in the gut, then fingerprinting might also spare patients a repeat small intestinal biopsy. The changes in coeliac disease need to be carefully distinguished from other ridge abnormalities, but this has in practice been found to be fairly simple, provided that the prints are taken carefully by an experienced operator with the correct mat- erials. It would be quite impossible to detect subtle ridge changes with inkless methods (Cherrill, 1954, p. 151), which are barely adequate for pattern classification let alone for a study of fingerprint minutiae. The type of paper used is also important, as if the ink is excessively absorbed then the ridges 'will not be clear enough for close study.

Further long-term studies are being made with quantitative methods of assessing ridge changes in coeliac disease and correlating these with changes in the small-bowel villi and other clinical criteria.

We are grateful to the many doctors who permitted us to study patients under their care, and to the patients themselves, who were most helpful.

Requests for reprints should be sent to Dr. T. J. David, Bristol Royal Infirmary, Bristol BS2 $8 \mathrm{HW}$.

\section{REFERENCES}

Chatterjee, S. K. (1967). Finger, Palm and Sole Prints, 2nd edn., p. 7 Calcutta, Kosa.

Cherrill, F. R. (1950). Nature, 166, 581

Cherrill, F. R. (1954). The Finger Print System at Scotland Yard. London, H.M.S.O.

Croft, D. N., Loehry, C. A., and Creamer, B. (1968). Lancet, 2, 68.

Cummins, H. (1967). Finger Print and Identification Magazine, November, p. 25.

Cummins, H. (1970). Finger Print and Identification Magazine, March, p. 6 Cummins, H., and Midlo, C. (1961). Finger Prints, Palms and Soles, p. 37 New York, Dover.

Federal Bureau of Investigation (United States) (1963). The Science of Fingerprints. Washington, U.S. Government Printing Office.

Galton, Sir F. (1965). Finger Prints, p. 59. New York, Da Capo.

Home Office (1960). Instructions in the Method of Taking Finger and Palm Prints. London, H.M.S.O.

Verbov, J. (1970). Fournal of Investigative Dermatology, 54, 261.

\title{
Fibrosing Alveolitis Associated with Renal Tubular Acidosis
}

\author{
A. M. S. MASON, ${ }^{*}$ M.B., M.R.C.P. ; M. B. MCILLMURRAY, $\dagger$ M.B., B.S. ; P. L. GOLDING, $\ddagger$ M.B., M.R.C.P. \\ D. T. D. HUGHES, $\$ B.M., M.R.C.P.
}

\begin{abstract}
Ummary: The discovery of a case of renal tubular acid$\checkmark$ osis and fibrosing alveolitis led to the investigation of 19 further patients. Abnormal pulmonary function tests were found in a further four patients with overt renal tubular acidosis and in four out of eight patients with "incomplete" renal tubular acidosis. The response to an ammonium chloride test in seven patients with cryptogenic fibrosing alveolitis was normal. Those patients with a defect of both renal acidification and pulmonary gas transfer had concurrent autoimmune diseases such as Sjögren's syndrome and primary biliary cirrhosis. It is suggested that the renal and pulmonary abnormalities may be part of a systemic disorder capable of affecting many organs. Moreover, hyperglobulinaemia and autoantibodies in these patients further suggests that immunological mechanisms are concerned in the pathogenesis of these abnormalities.
\end{abstract}

\section{Introduction}

Fibrosing alveolitis may be associated with hyperglobulinaemia (Hobbs and Turner-Warwick, 1967) and the presence of autoantibodies (Turner-Warwick and Doniach, 1965). Possibly autoimmune processes are concerned in the pathogenesis of this disorder (Mackay and Ritchie, 1965), and

\footnotetext{
* Formerly Research Assistant, Southampton General Hospital. f Formerly Senior House Officer, The London Hospital, London E.1. Senior Lecturer in Medicine, The London Hospital, London E.1. Requests for reprints to Dr. D. T. D. Hughes.
}

the concurrence of fibrosing alveolitis with other autoimmune diseases such as rheumatoid arthritis, Sjögren's syndrome, Hashimoto's thyroiditis, and active chronic hepatitis has been reported (Turner-Warwick, 1968; Scadding, 1969).

Renal tubular acidosis similarly may be associated with hyperglobulinaemia (Morris and Fudenberg, 1967) and autoantibodies (Talal et al., 1968). Diseases recorded as occurring with renal tubular acidosis include Sjögren's syndrome (Shearn and Tu, 1965), Hashimoto's thyroiditis (ClinicoPathological Conference, 1968), active chronic hepatitis (Read et al., 1963), and hyperglobulinaemic purpura (Greenspan, 1949). The coexistence of all of these conditions with renal tubular acidosis has recently been reviewed (Mason and Golding, 1970).

In this paper the clinical and immunological investigation of one patient with renal tubular acidosis and fibrosing alveolitis is reported in detail. Because of this previously undescribed association, a further four patients with overt renal tubular acidosis and eight with "incomplete" renal tubular acidosis had their lung function and chest radiographs studied. The response to an acid load was measured in seven patients with cryptogenic fibrosing alveolitis. Immunological studies and investigations for the presence of other autoimmune diseases were performed in all patients.

\section{Patients and Methods}

The patients selected for investigation were divided into three groups. Group A consisted of five patients with overt renal tubular acidosis-one of these (Case 1) is described in 
detail. Group B consisted of eight patients with "incomplete" renal tubular acidosis who were diagnosed when a series of patients with hyperglobulinaemia were investigated. Group C consisted of seven patients who presented with the clinical, radiological, and physiological evidence characteristic of fibrosing alveolitis; the radiological changes were a ground-glass appearance in three, a reticular pattern in one, nodular in one, and reticulonodular in two; in one case an open lung biopsy was performed which showed extensive alveolar fibrosis resembling the "mural" type of fibrosing alveolitis (Scadding and Hinson, 1967).

It was considered unnecessary to perform an acid load in subjects with an overt acidosis (plasma bicarbonate less than $20 \mathrm{mEq} / \mathrm{l}$.) while passing urine with a $\mathrm{pH}$ greater than 6 (group A). In the others an ammonium chloride test was performed with the method of Wrong and Davies (1959). In normal subjects the urine $p H$ should fall below 5.2, the maximal titratable acidity (Max. T.A.) should be above $24 \mu \mathrm{Eq} / \mathrm{min}$., and the maximal ammonium excretion (Max. $\mathrm{NH}_{4}$ ) above 33 $\mu \mathrm{Eq} / \mathrm{min}$.

Pulmonary function tests and a chest $x$-ray examination were done on all patients. Vital capacity and the forced expiratory volume in one second $\left(\mathrm{FEV}_{1}\right)$ were measured with a Vitalograph spirometer (Drew and Hughes, 1969). Transfer factor (diffusing capacity) was measured with the single breath carbon monoxide method described by Ogilvie et al. (1957) with modifications suggested by Jones and Meade (1961) and Cotes (1968). Predicted values were taken from Cotes (1968). Correction for a lowered haemoglobin value was made where necessary (Cotes and Hall, 1968; Cotes, 1970).

The immunological investigation of patients in groups $A$ and B were done at St. George's Hospital, London, and the Bournemouth Autoimmune Laboratory, and in group $\mathrm{C}$ at the London Hospital. The serum immunoglobulins in the first two groups was measured on an Immunoplate with the standards supplied by the manufacturer (Baxter Co., Thetford). Those from patients in group $\mathrm{C}$ were estimated with a Partigan immunodiffusion plate (Behringwerke) with standards supplied by Hoechst Pharmaceuticals. Serum rheumatoid factor was detected in patients in groups A and B by a slide screening test using Rheumatex (Colab Laboratories, Chicago, Illinois) and in group C by FII latex particle test. Thyroglobulin tanned red cell haemagglutination was measured in all patients by the method of Fulthorpe et al. (1961). The immunofluorescent studies were done with the staining method of Coons and Kaplan (1950), a 1 in 10 dilution of the patient's serum in groups $A$ and $B$ and $a 1$ in 4 dilution in group $C$ being used. All patients were investigated for the presence of Sjögren's syndrome, hyperglobulinaemic purpura, a peripheral neuropathy, autoimmune thyroid disease, and autoimmune liver disease.

\section{Case 1}

A housewife aged 30 was admitted to the London Hospital in 1961 complaining of pain in the hips and chest. Biochemical investigation showed a hyperchloraemic acidosis and hypocalcaemia while passing urine with a pH greater than 6. There was radiological evidence of nephrocalcinosis and pseudofractures in the ribs and pelvis. Osteomalacia secondary to renal tubular acidosis was diagnosed and treatment was started with potassium citrate and calciferol. Five years later she had recurrent swelling of the parotid glands and complained of dryness of the eyes and mouth. A diagnosis of keratoconjunctivitis sicca was confirmed by the rose bengal and Schirmer tests. There was no evidence of rheumatoid arthritis.

One year later she was admitted to hospital complaining of shortness of breath. She was cyanosed, the fingers were clubbed, and there were scattered crepitations over both lower zones. A chest $x$-ray film showed diffuse reticulonodular shadowing over both lung fields. Pulmonary function tests showed a reduced vital capacity and transfer factor. Histological examination of a drill biopsy specimen of the lurg showed in some areas pronounced alveolar fibrosis and in others pronounced infiltration with large mononuclear cells with granular cytoplasm. The appearance thus represented a mixture of both the "mural" and "desquamative" types of fibrosing alveolitis (Scadding and Hinson, 1967). Precipitin tests showed a positive reaction to budgerigar serum, and for 18 months before this admission she had kept a budgerigar. The severity of her clinical condition and the degree of impairment of pulmonary function was thought to contraindicate an inhalation challenge test. Hepatosplenomegaly and a generalized lymphadenopathy were also detected. A biopsy specimen of a supraclavicular node, $1 \mathrm{~cm}$. in diameter, showed a complete loss of architecture with replacement by diffuse histiocyte and reticulum cell proliferation consistent with a diagnosis of pseudolymphoma (Talal et al., 1967). Treatment was started with prednisone in July 1967. She responded dramatically with loss of lymphadenopathy and improved pulmonary function (Table I). When last seen, in June 1970, she was well, with no abnormal physical signs, and the improvement in pulmonary function had been maintained. A summary of her immunological investigations is included in Table III.

\begin{tabular}{|c|c|c|c|c|c|}
\hline \multirow[b]{2}{*}{ Date } & \multirow{2}{*}{$\begin{array}{c}\text { Vital } \\
\text { Capacity } \\
\text { \% Predicted) }\end{array}$} & \multirow[b]{2}{*}{$\underset{(\%)}{\mathrm{FEV}_{/} / \mathrm{VC}}$} & \multicolumn{2}{|c|}{ Transfer Factor } & \multirow[b]{2}{*}{$\begin{array}{l}\text { Prednisone } \\
\text { (mg. daily) }\end{array}$} \\
\hline & & & $\begin{array}{c}\text { Absolute } \\
\text { Value } \\
\text { (ml./mm. } \mathrm{mg} / \mathrm{Hin} / \\
\text { min.) }\end{array}$ & $\%$ Predicted & \\
\hline $\begin{array}{r}9 / 6 / 67 \\
22 / 6 / 67 \\
1 / 9 / 67 \\
29 / 9 / 67 \\
15 / 12 / 67 \\
12 / 6 / 70\end{array}$ & $\begin{array}{l}42 \\
38 \\
60 \\
63 \\
69 \\
97\end{array}$ & $\begin{array}{r}89 \\
95 \\
100 \\
97 \\
100 \\
90\end{array}$ & $\begin{array}{l}7 \\
7.5 \\
13 \\
12 \\
14 \\
13\end{array}$ & $\begin{array}{l}38 \\
39 \\
68 \\
64 \\
67 \\
65\end{array}$ & $\begin{array}{l}7 \\
20 \\
15 \\
12.5 \\
7.5\end{array}$ \\
\hline
\end{tabular}

\section{Results}

\section{Group A (Cases 1-5)}

Pulmonary Function Tests and Radiological Findings.In all five patients pulmonary function tests and chest radiographs were abnormal. Four had a reduced vital capacity and transfer factor with a normal FEV \%, suggesting fibrosing alveolitis. One (Case 3 ) had a reduced transfer factor with a normal vital capacity and FEV \%. Chest radiography showed reticulonodular shadowing in four patients and nodular shadowing in one (Table II).

Immunological Findings.-All five patients had hyperglobulinaemia and autoantibodies present in the serum. The results of these investigations are given in Table III.

\begin{tabular}{|c|c|c|c|c|c|c|c|c|c|c|}
\hline \multirow[b]{2}{*}{$\begin{array}{l}\text { Case } \\
\text { No. }\end{array}$} & \multicolumn{2}{|c|}{ Plasma } & \multicolumn{3}{|c|}{$\mathrm{NH}_{4} \mathrm{Cl}$ Test } & \multicolumn{4}{|c|}{ Lung Function } & \multirow[b]{2}{*}{ 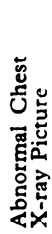 } \\
\hline & О人) & $\begin{array}{r}\overline{\bar{\sigma}} \\
\bar{U} \\
\bar{U}\end{array}$ & $\begin{array}{l}\frac{1}{a} \\
\dot{g} \\
\dot{\Sigma}\end{array}$ & 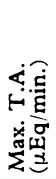 & 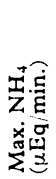 & 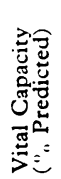 & 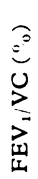 & 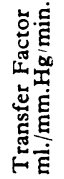 & 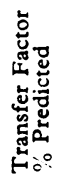 & \\
\hline
\end{tabular}


TABLE III.-Immunological Investigations

\begin{tabular}{|c|c|c|c|c|c|c|c|c|c|}
\hline & \multicolumn{3}{|c|}{$\begin{array}{c}\text { Immunoglobulins } \\
(\mathrm{mg} .100 \mathrm{ml} .)\end{array}$} & \multicolumn{6}{|c|}{ Autoantibodies } \\
\hline & IgG & IgA & $\mathrm{IgM}$ & 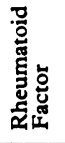 & 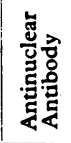 & 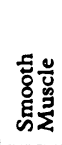 & 1 & $\stackrel{\circ}{3}$ & $\begin{array}{r}\stackrel{+}{u} \\
\dot{\alpha} \\
\stackrel{H}{H}\end{array}$ \\
\hline \multicolumn{10}{|c|}{ Group $A$} \\
\hline $\begin{array}{l}1 \\
2 \\
3 \\
4 \\
5\end{array}$ & $\begin{array}{l}2,600 \\
2,200 \\
7,800 \\
2,400 \\
2,800\end{array}$ & $\begin{array}{l}370 \\
410 \\
480 \\
470 \\
360\end{array}$ & $\begin{array}{r}100 \\
70 \\
1,200 \\
460 \\
960\end{array}$ & $\begin{array}{l} \pm \\
\pm \\
\pm \\
+\end{array}$ & $\begin{array}{l} \pm \\
\pm \\
\pm \\
+\end{array}$ & $\begin{array}{l}+ \\
+ \\
+\end{array}$ & : & $\begin{array}{l}- \\
\dot{t} \\
\dot{t}\end{array}$ & + \\
\hline \multicolumn{10}{|c|}{ Group B } \\
\hline $\begin{array}{r}6 \\
7 \\
8 \\
9 \\
10 \\
11 \\
12 \\
13\end{array}$ & $\begin{array}{l}3,200 \\
1,180 \\
1,730 \\
1,300 \\
1,700 \\
2,000 \\
2,700 \\
1,550\end{array}$ & $\begin{array}{l}900 \\
570 \\
380 \\
250 \\
350 \\
360 \\
350 \\
260\end{array}$ & $\begin{array}{r}54 \\
355 \\
1,600 \\
\neq \\
150 \\
280 \\
310 \\
100\end{array}$ & $\begin{array}{l}\dot{+} \\
\dot{+} \\
\dot{+} \\
+ \\
\dot{+} \\
+ \\
+\end{array}$ & $\begin{array}{l}+ \\
- \\
- \\
+ \\
- \\
- \\
-\end{array}$ & + & ; & $\begin{array}{l}+ \\
+ \\
+ \\
+ \\
+\end{array}$ & + \\
\hline \multicolumn{10}{|c|}{ Group C } \\
\hline $\begin{array}{l}14 \\
15 \\
16 \\
17 \\
18 \\
19 \\
20\end{array}$ & $\begin{array}{l}1,120 \\
1,400 \\
1,960 \\
2,660 \\
1,960 \\
1,120 \\
2,660\end{array}$ & $\begin{array}{l}304 \\
520 \\
520 \\
680 \\
304 \\
152 \\
152\end{array}$ & $\begin{array}{r}135 \\
180 \\
110 \\
235 \\
75 \\
75 \\
425\end{array}$ & $\begin{array}{l}+ \\
+ \\
\div \\
+ \\
+\end{array}$ & $\begin{array}{l}= \\
= \\
\cdots \\
- \\
-\end{array}$ & $\ldots$ & $i$ & $\begin{array}{l}\overline{+} \\
\overline{+} \\
\overline{-}\end{array}$ & + \\
\hline
\end{tabular}

*Mito = Mitochondrial antibody.

TT.T.R.C. = Thyroglobulin tanned red cell haemagglutination. $\$$ Monomer IgM only was detected in this patient.

Normal range (groups $A$ and $B$ ): IgG $=600-1,200, \operatorname{IgA}=170-410,1 g M=50-110$. Normal range (group $\mathrm{C}$ ): $\mathrm{IgG}=800-1,800$, IgA $=120-400$, IgM $=80-170$.

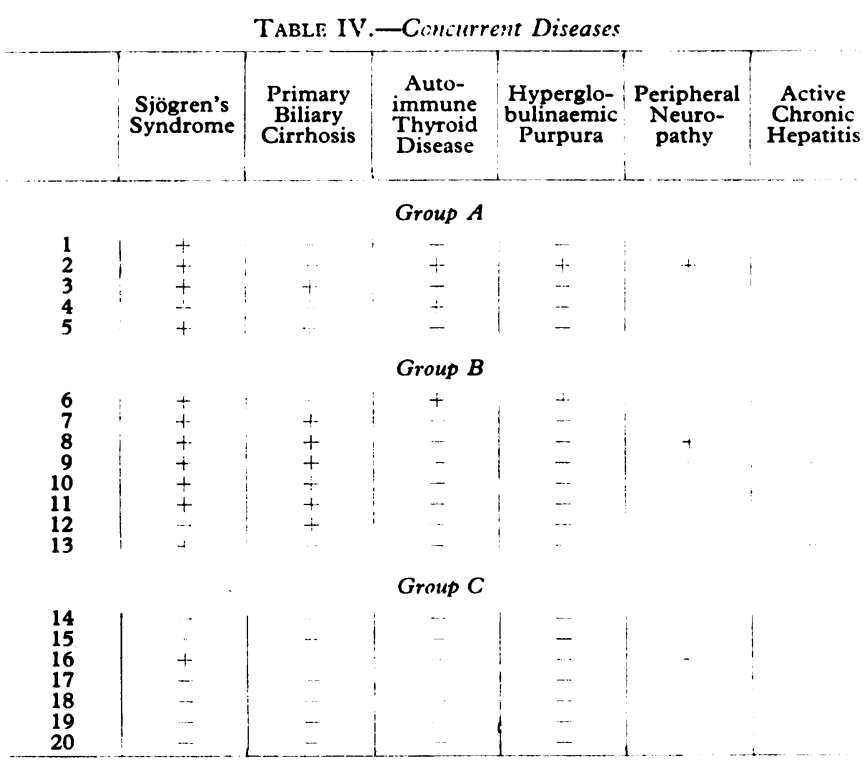

Associated Diseases.-The presence of Sjögren's syndrome, primary biliary cirrhosis, autoimmune thyroid disease, hyperglobulinaemic purpura, and peripheral neuropathy is shown in Table IV. Up to four of these conditions appeared in any one patient.

\section{Group B (Cases 6-13)}

Pulmonary Function Tests and Radiological Findings.Four of the eight patients had abnormal pulmonary function tests and three had abnormal chest radiographs. Three (Cases 6-8) had a reduced vital capacity and transfer factor with a normal FEV \% consistent with a diagnosis of fibrosing alveolitis. Case 9 had a reduced transfer factor but vital capacity and FEV \% were normal. Chest radiography showed reticular shadowing in Case 7 and reticulonodular shadowing in Cases 6 and 9. The radiograph in Case 8 was normal (Table II).

Immunological Findings.-All eight patients had hyperglobulinaemia and autoantibodies were present in the serum. The results of these investigations are given in Table III.

Associated Diseases.-The other conditions present are shown in Table IV. Up to three of these appeared in any one patient.

\section{Group C (Cases 14-20)}

Renal Acidification.-All seven patients responded normally to an aral dose of ammonium chloride and were able to acidify their urine below a $\mathrm{pH}$ of 5.2 (Table II).

Immunological Investigations.-Five of the seven had hyperglobulinaemia. The results of these investigations are shown in Table. III. One patient (Case 17) had raised IgG, IgA and IgM levels.

Associated.Diseases.-Only one of the seven patients showed evidence of concurrent autoimmune disease. This patient (Case 16) had Sjögren's syndrome and a peripheral neuropathy (Table IV).

\section{Discussion}

The presenting case (No. 1) had renal tubular acidosis and six years later developed diffuse pulmonary disease with a gas transfer defect. There was histological evidence of an alveolar lesion. Although she had kept a.budgerigar, and had avian precipitins in her serum, she resembled other cases in having raised immunoglobulins and autoantibodies.

Renal tubular acidosis is a disorder of function in which there is an inability of the renal tubule to acidify urine normally which is out of proportion to any reduction in the glomerular filtration rate. This abnormality may present as an overt hyperchloraemic acidosis or be detected only during an ammonium chloride test (Wrong and Davies, 1959). All the patients with renal tubular acidosis in this series had hyperglobulinaemia and autoantibodies in the serum. This syndrome has been called hyperglobulinaemic renal tubular acidosis by McCurdy et al. (1967). The five patients in group A had pulmonary function and radiological changes compatible with a diagnosis of fibrosing alveolitis. The transfer capacity was reduced in four of the eight patients in group B, and three of these had associated radiological changes.

Fibrosing alveolitis is a term introduced by Scadding (1964, 1969) to designate the clinicopathological syndrome previously called diffuse interstitial pulmonary fibrosis. Pulmonary function tests show a restrictive ventilatory capacity with impaired gas transfer but normal airways resistance. The aetiology of this disorder is not known, but possibly autoimmune processes are involved in the pathogenesis of some cases (Mackay and Ritchie, 1965). The seven patients in group C fulfil these diagnostic criteria, but no defect of renal acidification was detected.

Raised serum immunoglobulin levels have been recorded in fibrosing alveolitis, Hobbs and Turner-Warwick (1967) finding this in one or more classes of immunoglobulins in 22 out of 32 patients $(69 \%)$. In our patients one class of immunoglobulin only was raised in 14 sera: the $\mathrm{IgG}$ fraction in $8, \operatorname{IgA}$ in 3 , and $\operatorname{IgM}$ in 3 . Five of the seven patients $(71 \%$ ) in group $C$ had an increase in one or more classes of immunoglobulin.

Autoantibodies have often been detected in patients with fibrosing alveolitis, and Turner-Warwick and Doniach (1965) found one or more autoantibodies in over half of the patients they investigated. Rheumatoid factor was present in $49 \%$, antinuclear antibody. in $28 \%$, and thyroglobulin antibody. in 
$12 \%$. Autoantibodies were found in five of the seven patients $(71 \%)$ in group C-the five with raised levels of immunoglobulins. Rheumatoid factor was present in three, mitochondrial antibody in one, and a raised thyroglobulin tanned red cell titre in one. There was no clinical or biochemical evidence of autoimmune liver or thyroid disease in either of the last two patients.

The immunoglobulin levels have been measured in four series of patients with hyperglobulinaemic renal tubular acidosis (Morris and Fudenberg, 1967; Wilson et al., 1967; McCurdy et al., 1967; Talal et àl., 1968). Sixteen patients were investigated in all, and the serum IgG level was raised in $15, \operatorname{Ig} A$ in 10 , and $\operatorname{IgM}$ in five. All 13 cases with renal tubular acidosis in this series (groups $A$ and $B$ ) had hyperglobulinaemia. The IgG level was raised in 12 and the IgA level in four. Eight patients had a raised IgM level, and they all had concurrent primary biliary cirrhosis; as diagnosed by clinical, biochemical, and histological investigations. This condition is often associated with an increase in the serum IgM concentration (Feizi, 1968). One patient (Case 9) who had a large concentration of monomer IgM (Martin, 1969) present in the serum also had primary biliary cirrhosis.

The nine patients with hyperglobulinaemic renal tubular acidosis investigated by McCurdy et al. (1967) and Talal et al. (1968) were all shown to have autoantibodies in the serum. All 13 patients with hyperglobulinaemic renal tubular acidosis in this series (groups A and B) had autoantibodies present in their serum. Rheumatoid factor was detected in 11 and antinuclear antibody in five. Mitochondrial antibody was present in eight patients, and they all had concurrent primary biliary cirrhosis, a condition in which mitochondrial immunofluorescence is often found (Doniach et al., 1966). Smooth muscle antibody was detected in three patients, and two of them had autoimmune liver disease. The thyroglobulin tanned red cell titre was raised in three patients, and two of these had autoimmune thyroid disease. No difference in the pattern of autoantibodies was detected between the patients with and those without a transfer defect.

Hashimoto's thyroiditis, active chronic hepatitis, and Sjögren's syndrome have all been described in patients with fibrosing alveolitis (Turner-Warwick, 1968; Scadding, 1969), but the frequency with which these disorders occur together has not been determined. In our series of seven patients with fibrosing alveolitis only one showed clinical evidence of concurrent disease. This patient (Case 16) had Sjögren's syndrome and a peripheral neuropathy.

All the 13 patients with hyperglobulinaemic renal tubular acidosis had at least one other disease, thought to be autoimmune in nature. Twelve had keratoconjunctivitis sicca and xerostomia, and though many had arthralgia none of them had rheumatoid arthritis. Nine (Cases 3-5 and 7-12) had primary biliary cirrhosis. Though active chronic hepatitis has been described in association with fibrosing alveolitis (T.urner-Warwick, 1968), primary biliary cirrhosis has not. Three of our cases had autoimmune thyroid disease, two had hyperglobulinaemic purpura, and two a peripheral neuropathy. The concurrence of these disorders with renal tubular acidosis has been reviewed (Mason and Golding, 1970).

A pulmonary gas transfer defect was found in each of five patients with overt renal tubular acidosis and in four out of eight patients with the "incomplete" form Pulmonary function abnormalities are thus common in patients with hyperglobulinaemic renal tubular acidosis when this is associated with other autoimmune diseases. Patients with hyperglobulinaemic renal tubular acidosis alone were not available for investigation, but such a study would be of obvious interest. Conversely, in our small group of patients with cryptogenic fibrosing alveolitis there was a low incidence of associated diseases, but no cases of renal tubular acidosis. Hence probably, at least in those patients with both hyperglobulinaemic renal tubular acidosis and fibrosing alveolitis, the abnormalities of renal and pulmonary function are part of a systemic disorder capable of affecting many organs. The presence of autoantibodies and hyperglobulinaemia suggests that immunological processes are concerned in their pathogenesis. There may therefore be some justification for the introduction of the term "hyperglobulinaemic fibrosing alveolitis" to distinguish these cases from those of a different aetiology. Further clinical and experimental studies on patients with renal tubular acidosis and fibrosing alveolitis are required to elucidate the precise pathological mechanisms and interrelationships concerned in the pathogenesis of these disorders.

We should like to thank the Physicians of the Wessex Region and the London Hospital for permission to study patients under their care; Dr. C. Franglen, Mr. R. Lloyd, and Dr. J. Perrin for performing the immunological investigations; Dr. W. M. MacLeod for pulmonary function studies on patients in the Wessex Region; and Dr. A. H. E. Marshall, of the London Hospital, for reviewing the histological sections from Case 1 .

We are grateful for grants. received from the Medical Research Council (A.M.S.M.) and the Free Funds of the London Hospital (P.L.G.)

\section{REFERENCES}

Clinico-Pathological Conference (1968). New England fournal of M.dicine, 279, 705 .

Coons, A. H., and Kaplan, M. H. (1950). Journal of Experimental Medicine, 91, 1 .

Cotes, J.. E. (1968). Lung Function, 2nd edn., p. 239. Oxford, Blackwell Cotes, J. E. (1970). In press.

Cotes, J. E., and Hall, A. M. (1968). Bulletin de Physio-pathologie Respiratoire, 4, 691 .

Doniach, D., Roitt, I. M., Walker, J. G., and Sherlock, S. (1966). Clinical and Experimental Immunology, 1, 237

Drew, C. D. M., and Hughes, D. T. D. (1969). Thorax, 24, 703.

Feizi, T. (1968), Gut, 9, 193.

Fulthorpe, A. J., Roitt, I. M., Doniach, D., and Couchman, K. (1961). fournal of Clinical Pathology, 14, 654 .

Greenspan, E. M. (1949). Archives of Internal Medicine, 83, 271.

Hobbs, J. R., and Turner-Warwick, M. (1967). Clinical and Experimental Immunology, 2, 645.

Jones, R. S., and Meade, F. (1961). Quarterly fournal - of Experimental Physiology, 46, 131.

McCurdy, D. K., Cornwell, G. G., and DePratti, V. J. (1967). Annals of Internal Medicine, 67, 110 .

Mackay, I. R., and Ritchie, B. (1965). Thorax, 20, 200.

Martin, N. H. (1969). Fournal of Clinical Pathology, 22, 117

Mason, A. M. S., and Golding, P. L. (1970). British Medical fournal, 3, 143.

Morris, R. C., and Fudenberg, H. H. (1967). Medicine, 46, 57.

Ogilvie, C. M., Forster, R. E., Blakemore, W. S., and Morton, J. W. (1957). fournal of Clinical Investigation, 36, 1.

Read, A. E., Sherlock, S., and Harrison, C. V. (1963). Gut, 4, 378.

Scadding, J. G. (1964). British Medical fournal, 2, 686.

Scadding, J. G. (1969). Proceedings of the Royal Society of Medicine, 62, 227.

Scadding, J. G., and Hinson, K. F. W. (1967). Thorax, 22, 291.

Shearn, M. A., and Tu, W. H. (1965). American fournal of Medicine, 39, 312.

Talal, N.; Sokoloff, L., and Barth, W. F. (1967). American fournal of Medicine, 43, 50.

Talal, N., Zisman, E., and Schur, P. H. (1968). Arthritis and Rheumatism, 11,774 .

Turner-Warwick, M. (1968). Quarterly fournal of Medicine, 37, 133.

Turner-Warwick, M., and Doniach, D. (1965). British Medical fournal, 1, 886.

Wilson, I. D., Williams, R. C., and Tobian, L. (1967). American fournal of Medicine, 43, 356.

Wrong, O., and Davies, H. E. F. (1959). Quarterly fournal of Medicine, 28, 